\title{
Distribution of Vitronectin in the Embryonic Chick Heart During Endocardial Cell Migration*
}

\author{
Hiroshi Sumida ${ }^{1}$, Harukazu Nakamura ${ }^{2}$ and Yukio Satow ${ }^{1}$ \\ Department of Geneticopathology ${ }^{1}$, Research Institute for Nuclear Medicine and Biology, Hiroshima University, Hiroshima; \\ and Department of Biology², Kyoto Prefectural University of Medicine, Kyoto, Japan
}

Received May 31, 1989

Summary. In the early phase of heart development, the endocardial cells migrate into the truncal swellings and atrioventricular (AV) cushions, and become mesenchymal cells. Vitronectin is a glycoprotein which is thought to mediate cell migration. The present study demonstrates by immunohistochemistry the distribution of vitronectin in order to elucidate its contribution to endocardial cell migration in the developing chick heart.

At Hamburger and Mamilton's stage 23, the network of fibrillar material filled the extracellular space of both truncal swellings and AV cushions. The fibrillar network has been thought to be a matrix for endocardial cell migration. The network was stained with the anti-vitronectin antibody. At stage 29, the swellings and cushions were packed with mesenchymal cells, though immunoreactivity to the antibody was still observed in the extracellular matrix. The myocardium facing the AV cushions reacted to the antibody, but the myocardium surrounding the truncus arteriosus did not. The intensity of the immunohistochemical staining of the myocardium facing the $\mathrm{AV}$ cushions increased and reached a peak at stages 24 to 26 , and then became weak by stage 29. The endocardial sheet, aortico-pulmonary septum and developing tunica media of the great arteries were not stained by the antibody at any stage.

These results strongly suggest that vitronectin is involved in the migration of endocardial cells, and that the myocardium facing the AV cushions produces vitronectin.

In the early phase of heart development, the endocardial cells of the conotruncal area and atrioventricular (AV) canal migrate into the conotruncal swellings and AV cushions, respectively, and become mesenchymal cells in the swellings or cushions (MARKWALD et al., 1975, 1977; FITZHARRIS and MARKWALD, 1982; FUNDERBURG and MARKWALD, 1986). The development of the swellings and cushions is important in cardiac morphogenesis, and abnormal development of these structures causes cardiac malformations (reviewed by ОКАмото, 1988).

Fibronectin was reported to mediate the migration of the endocardial cells (ICARDO and MANASEK, 1984). However, it was recently reported that the migrating endocardial cells do not have the fibronectin receptor (DUBAND et al., 1986; SumidA et al., 1989a). This finding suggests that fibronectin is not involved in the migration of the endocardial cells, whereas neural crest cells which migrate into the aortico-pulmonary (AP) septum of the developing heart may closely interact with fibronectin (SUMIDA et al., 1989a, b).

Vitronectin is a glycoprotein which promotes cell spreading and attachment to the substratum in vitro (BARNES and SATO, 1980; BARnES and SILnUTZER, 1983; HAYMAN et al., 1983). Similar to fibronectin, vitronectin has a cell attachment site composed of the ArgGly-Asp (RGD) amino sequence (SUZUKI et al., 1985). The fibronectin-receptor does not bind to the synthetic peptides containing RGD, but the vitronectin-receptor does (reviewed RuOSLAHTI and PIERSCHBACHER, 1987). These results suggest that the affinity of vitronectin to its receptor is higher than that of fibronectin to its receptor. Thus, it was believed that vitronectin might play an important role for cell migration in vivo.

The present paper demonstrates the distribution of vitronectin in the developing chick heart, in order to elucidate the possibility of vitronectin contributing to the migration of endocardial cells.

\footnotetext{
*This work was supported in part by a Grant-in-Aid for Encouragement of Young Scientists (63770017, to H.S.) from the Ministry of Education, Science and Culture, Japan.
} 


\section{MATERIALS AND METHODS}

Fertilized chicken eggs were incubated at $38^{\circ} \mathrm{C}$ in a humidified atmosphere. From days 4 to 6 of incubation, the embryos were fixed with $4 \%$ paraformaldehyde in $0.1 \mathrm{M}$ phosphate buffered saline (PBS) for $24 \mathrm{~h}$ at room temperature. After staging according to HAMBURGER and HAMilTon (1951), the embryos were dehydrated through a graded series of ethanol, cleared in xylene and then embedded in Tissue Prep (Fisher Scientific Co., USA). Cross sections of the truncus arteriosus were cut at $8 \mu \mathrm{m}$, mounted on glass slides and deparaffinized in xylene.

Immunohistochemical procedures were performed at room temperature. As chick vitronectin and an antichick vitronectin antibody were not available, an antivitronectin antibody (Chemicon International, Inc., USA) which was raised against human plasma vitronectin in rabbits was used as a primary antibody. We concluded from two results that the immunoreactivity to the antibody on the sections revealed the localization of vitronectin. First, the anti-vitronectin antibody bound to spots of proteins from 7-day-old

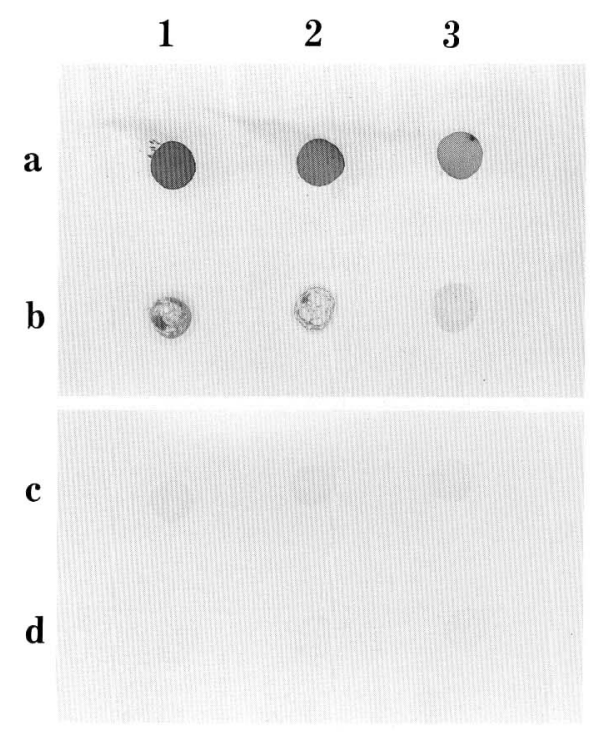

Fig. 1. Western dot blotting. Spots a-1, c-1: $5 \mu \mathrm{g}, \mathbf{a}-\mathbf{2}$, c-2: $2 \mu \mathrm{g}, \mathbf{a}-\mathbf{3}, \mathbf{c}-3: 0.5 \mu \mathrm{g}$ of human vitronectin. Spots b-1, 2,3 and $\mathbf{d}-1,2,3$ : proteins from 7 -day-old chick embryos diluted serially. The anti-vitronectin antibody bound to the spots of human vitronectin and chick embryonic proteins $(\mathbf{a}-1,2,3$ and $\mathbf{b}-\mathbf{1}, \mathbf{2}, \mathbf{3})$, but that which was preincubated with human vitronectin overnight did not bind to the spots $(\mathbf{c}-\mathbf{1}, \mathbf{2}, \mathbf{3}$ and $\mathbf{d}-1,2,3)$. chick embryos by the western dot blotting method, but the antibody which was pre-incubated with human vitronectin (Iwaki Glass, Japan) bound only negligibly (Fig. 1). Second, staining on the sections with the antibody which was pre-incubated with human vitronectin was negligible.

The sections were incubated for $1 \mathrm{~h}$ with the antibody diluted 30 times. After washing in PBS for removing the non-bound antibody, the sections were incubated for 20 min with biotinylated anti-rabbit IgG followed by incubation with peroxidase labeled avidin (StrAviGen; BioGenex, USA). The sections were developed with $0.02 \%$ diaminobenzidine- $0.002 \% \quad \mathrm{H}_{2} \mathrm{O}_{2}$ for $10 \mathrm{~min}$ and were stained with hematoxylin.

\section{Scanning electron microscopy}

Embryos at stage 23 were fixed in $2.5 \%$ glutaraldehyde in $0.1 \mathrm{M}$ phosphate buffer containing $0.5 \%$ cetyl pyridinium chloride for $4 \mathrm{~h}$ at room temperature. The hearts were excised with small scissors in $0.1 \mathrm{M}$ phosphate buffer and postfixed in $1 \% \mathrm{OSO}_{4}$ in the same buffer for $1 \mathrm{~h}$ at $4^{\circ} \mathrm{C}$. The specimens were dehydrated through a graded series of ethanol, infiltrated with isoamyl acetate and then critical point dried using liquid $\mathrm{CO}_{2}$. The specimens were coated with gold and viewed with a Hitachi S-430 scanning electron microscope operated at $20 \mathrm{kV}$.

\section{RESULTS}

We examined embryos at stages 23, 24, 26, 28 and 29. The embryos showed obvious immunoreactivities to the anti-vitronectin antibody in the truncal swellings and $\mathrm{AV}$ cushions at these stages.

\section{Truncus arteriosus}

At stage 23, cells were sparsely scattered in the truncal swellings (Figs. 2a, 4a). These cells might be endocardial cells migrating toward the myocardium (MARK. WALD et al., 1975, 1977; FitzhARRIS and MARKWALD, 1982; Funderburg and Markwald, 1986). Although migrating cells derived from the endocardium in the swellings or cushions are no longer endocardial cells, we considered these cells as migrating endocardial cells for descriptive convenience. The extracellular space at this stage was filled with a fibrillar network. The cells in the swellings were enmeshed in the fibrillar network (Fig. 3a). Some parts of the network, as well as the migrating endocardial cells, were stained with the anti-vitronectin antibody. A weak immunoreactivity of the myocardium to the antibody was recog- 

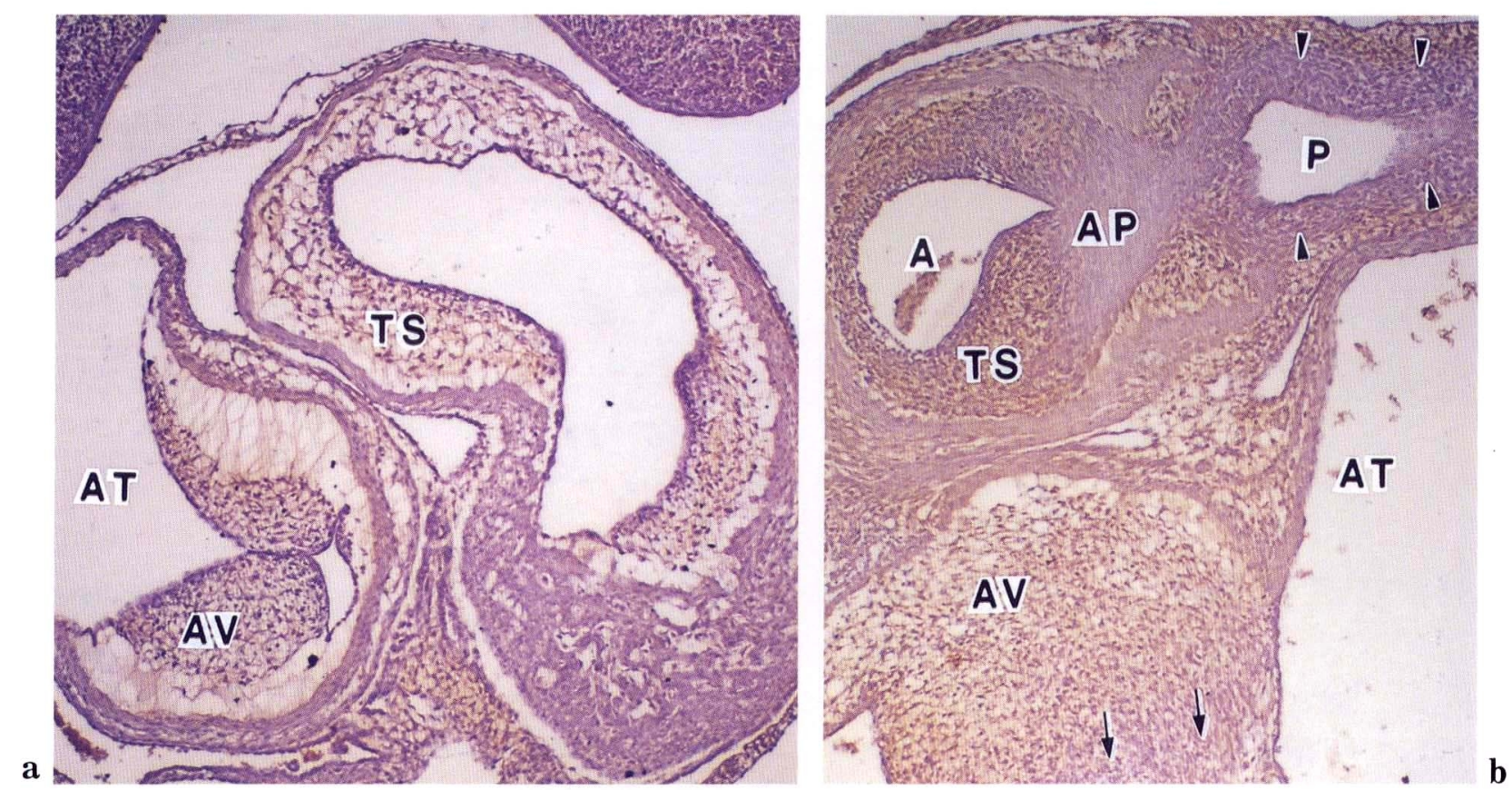

Fig. 2. Anti-vitronectin staining of the heart at stage $23(\mathbf{a}, \times 90)$ and stage $29(\mathbf{b}, \times 90)$ embryos. Mesenchymal cells are sparsely scattered in the truncal swellings (TS) and AV cushions $(A V)$ at stage 23 (a). At stage 29 (b), mesenchymal cells are packed in the swellings and cushions. The AP septum $(A P)$ is seen between the aortic $(A)$ and pulmonary $(P)$ lumens. At this stage, the AV cushions are fused (shown by arrows). The AV cushions are stained by the anti-vitronectin antibody, but in the fusing area, immunoreactivity to the antibody is weak. At both stages, immunoreactivity to the antibody is obvious in the swellings. The AP septum and developing tunica media (arrowheads) are not stained by the antibody. AT atrium.

nizable, but not so for the endocardial sheet (Fig. 4a).

At stages 24 and 26, mesenchymal cells increased in number, but were still scattered in the swellings. The staining pattern of the antibody was similar to that of the stage 23 embryos.

At the later stages (28 and 29), mesenchymal cells proliferated and filled up the swellings (Figs. 2b, 4b). The AP septum appeared in the swellings as a cellular condensation between the aortic and pulmonary lumens. The extracellular matrix of the swellings was well stained with the anti-vitronectin antibody; however, the AP septum and developing tunica media were not stained with the antibody (Figs. 2b, 4b).

\section{AV cushions}

At stage 23, cells filled half of the cushions (Figs. 2a, $5 \mathrm{a})$. These cells were located close to the fibrillar network. The myocardial side of the cushions was cell free, and was composed of only the fibrillar network (Fig. 3b). Similar to the truncal swellings, some but not all parts of the network were stained with the antibody (Figs. 2a, 5a). This staining pattern was general in the truncal swellings and AV cushions at all stages examined. Some amount of the antigen might be lost during dehydration, as it was reported that the network was water soluble (FITZHARRIS and MARKWALD, 1982). The myocardium which faces the cushions (Fig. 5a) was more intensely stained than the truncal myocardium (Fig. 4a).

At stage 24 (Fig. 5b), a larger number of mesenchymal cells filled the cushions. Some parts of the fibrillar network of the extracellular matrix were stained with the antibody. The myocardium which faces the cushion was clearly stained (Fig. 5b). This intense staining of the myocardium to the antibody was still seen at stage 26. Staining of the other parts of the ventricular myocardium was negligible at all stages examined.

At stages 28 and 29, the AV cushions were fully filled with the mesenchymal cells, and the superior and inferior cushions fused together (Fig. 2b). The mesenchymal cells were packed in the fusing area. Immunoreactivity of this area to the antibody was weak, though other parts of the cushions were obviously stained. 

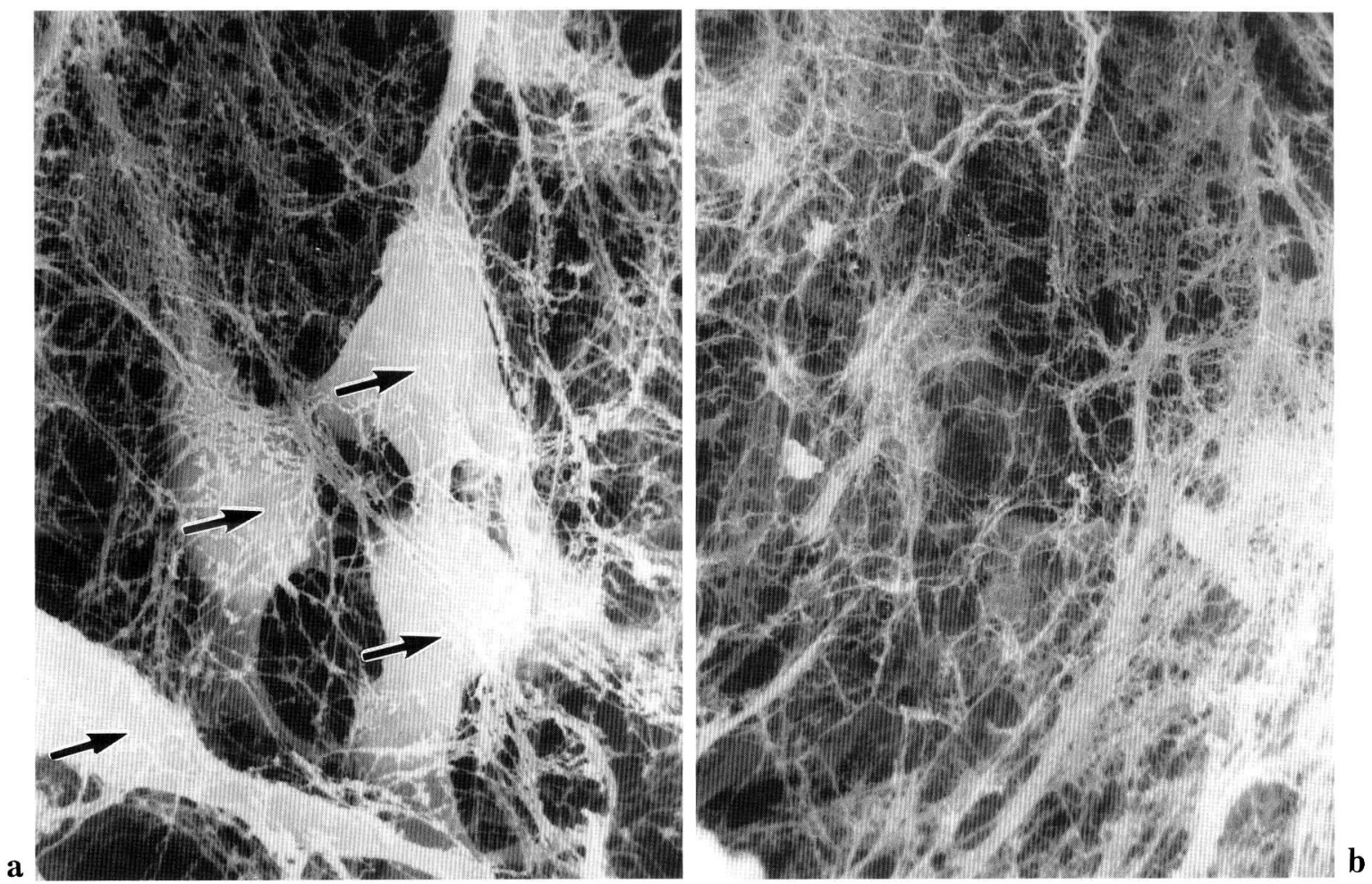

Fig. 3. Scanning electron micrographs of the truncal swelling (a) and AV cushion (b) at stage 23. A network of fibrillar material is seen. Migrating endocardial cells (arrows in a) are enmeshed in the network. At this stage, the fibrillar network fills the cell-free space of the AV cushions. $\times 2,800$

Immunoreactivity of the myocardium which faces the cushion had decreased by these stages (Fig. 2b).

\section{DISCUSSION}

Until the middle 1980s, fibronectin had been thought to mediate the migration of the endocardium (ICARDO and MANASEK, 1984). However, immunohistochemical studies (DUBAND et al., 1986; SuMIDA et al., 1989a) revealed that the migrating endocardial cells did not have the fibronectin receptor, suggesting that fibronectin is not involved in endocardial cell migration. This fact prompted us to look for another candidate for mediating the migration of endocardial cells. The most probable material was vitronectin. Vitronectin and fibronectin have a similar tripeptide at their cell recognition site, but the affinity of vitronectin to its receptor is much higher than that of fibronectin to its receptor (RUOSLAHTI and PIERSCHBACHER, 1987). Our results clearly showed that vitronectin was distributed in the extracellular matrix of the truncal swellings and AV cushions at the period of migration of the endocardial cells.
Another candidate to mediate the cell migration of endocardial cells is heparan sulfate. FUNDERBURG and MARKWALD (1986) suggested that heparan sulfate mediatedthe attachment and detachment of fibronectin connected to migrating endocardial cells to/from collagen distributed in the extracellular matrix. However, this suggestion assumes that fibronectin plays an important role for the migration of endocardial cells. In fact, fibronectin is produced by the migrating endocardial cells (FFRENCHCONSTANT and Hynes, 1988), whereas these cells have no fibronectin receptor. This phenomenon is difficult to understand. Fibronectin might be produced for binding collagen fibrils to thus arrange the physical pathway for endocardial cell migration.

The extracellular space of the swellings and cushions was filled with the fibrillar network. The fibrillar network, called the cardiac jelly fibril, has been thought to be significant in endocardial cell migration as a pathway (NAKAMURA and MANASEK, 1978). FITZHARRIS and MARKWALD (1982) reported a close interaction between migrating endocardial cells and the fibrils by a high voltage transmission electron microscopy. In the present study, the fibrillar network was 

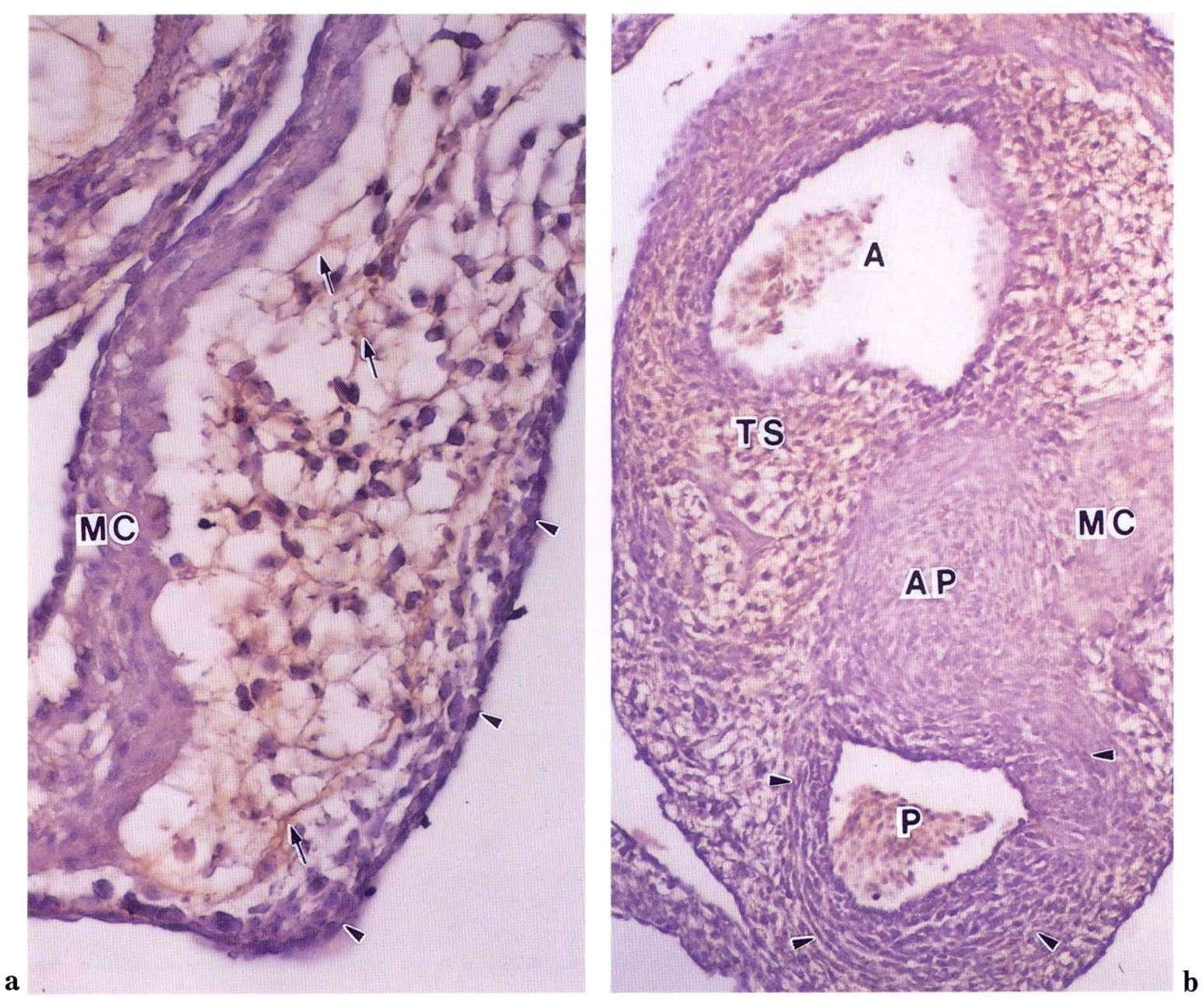

Fig. 4. Higher magnification of the truncus arteriosus of stage $23(\mathbf{a}, \times 370)$ and stage $29(\mathbf{b}, \times 185)$ embryos. In the younger embryo (a), the network of fibrillar material (arrows) fills the extracellular space. Some parts of the network are stained with anti-vitronectin antibody. The endocardial sheet (arrowheads in a), the AP septum $(A P)$ and developing tunica media (arrowheads in b) are not stained with the antibody. $M C$ myocardium, TS truncal swelling, $A$ aortic lumen, $P$ pulmonary lumen.

stained with the anti-vitronectin antibody. It is suggested from the result that vitronectin mediates the attachment of migrating endocardial cells to their pathway.

Some migrating endocardial cells were also stained with the anti-vitronectin antibody. The scanning electron micrograph showed that migrating endocardial cells were enmeshed in the fibrillar network. The positive staining pattern of migrating endocardial cells to the antibody might result from the close contact between cells and the fibrils.

It was also demonstrated that migrating endocardial cells in human embryos were stained by an antivitronectin receptor antibody (SUMIDA et al., in press). However, we have not checked the distribution of vitronectin receptors in chick embryos, because no antibody which recognizes the chick vitronectin receptor has been elaborated. Antibodies which were raised against mammalian vitronectin receptors could not be used for recognition of the chick vitronectin receptor, because the chick vitronectin receptor probably differs from that of mammals, as discussed below.

In order to elucidate the contribution of vitronectin to cell migration in the chick, we have to examine the vitronectin receptor. In birds, however, characteristics of the vitronectin receptor have not been clarified. We have tried to isolate the vitronectin receptor from chick embryos by a method of Pytela et al. (1987). As results, a 125/115 Kd protein complex was not eluted from the GRGDSP column, whereas the 

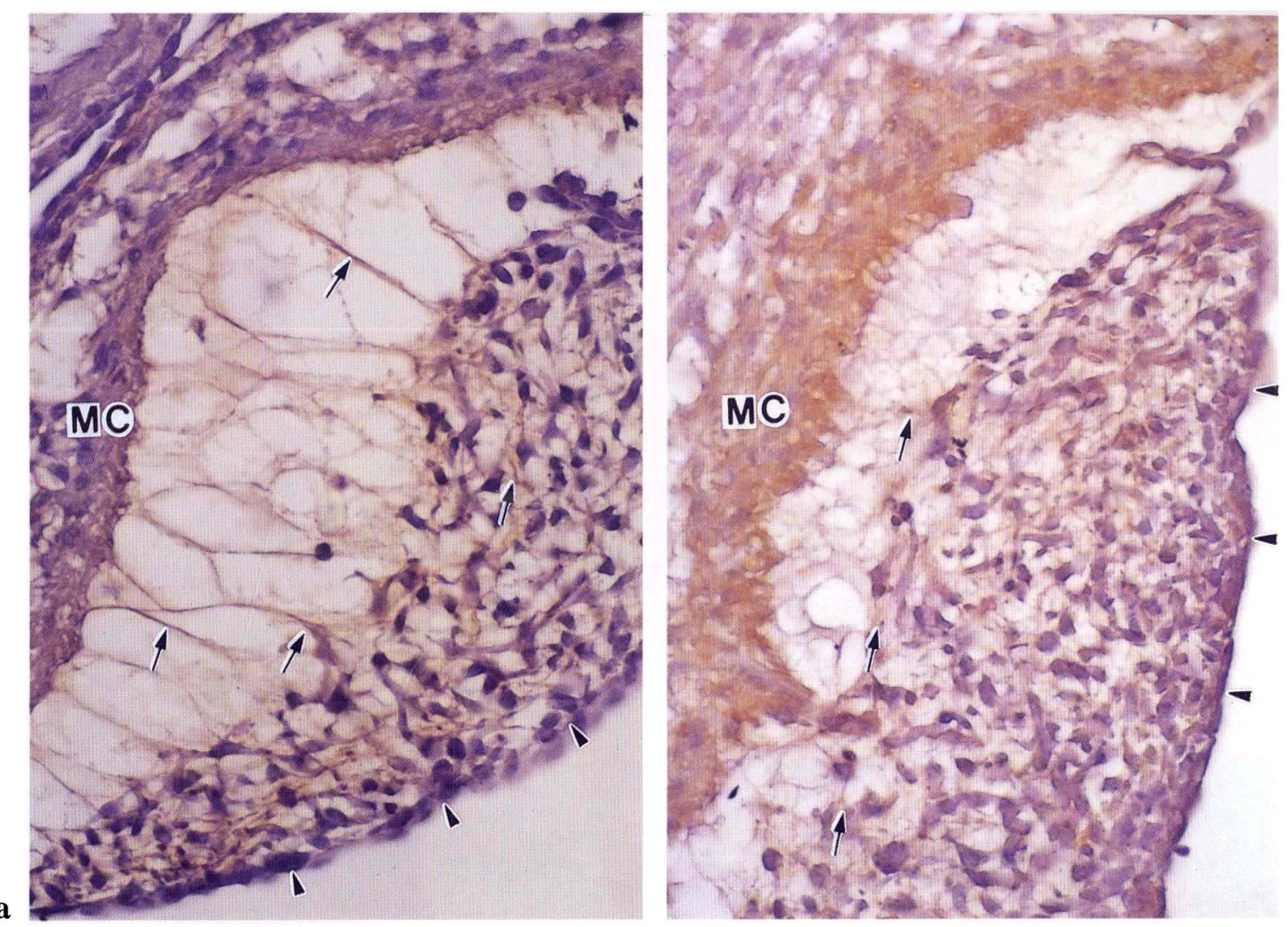

b

Fig. 5. Higher magnification of the AV cushions of stage $23(\mathbf{a}, \times 370)$ and stage $24(\mathbf{b}, \times 370)$ embryos. At stage 23 (a), half of the space in the cushion is not filled by mesenchymal cells. At the later stage (b), most of the space in the cushion is filled by mesenchymal cells. The fibrillar network fills the extracellular space of the cushions (arrows). Some parts of the network are stained with the anti-vitronectin antibody. The endocardial sheet (arrowheads) is not stained by the antibody. Note the immunoreactivity of the myocardium $(M C)$ facing the cushions.

protein complex from the human placenta revealed an affinity to the same column (Fig. 6). This result indicates that the avian vitronectin receptor is different from that of mammals. Further study is necessary to elucidate the details of interaction between the avian vitronectin receptor and the ligand. ${ }^{* *}$

The myocardium facing the AV cushions was stained by the anti-vitronectin antibody, but the myocardium surrounding the truncus arteriosus was not stained. This observation might be important in indicating that part of the myocardium was producing

**Very recently, HyNES et al. (J. Cell Biol. 109: 409-420, 1989) succeeded in eluting a protein complex from the RGD affinity column using ${ }^{125}$ I labeled fibroblasts of the chicken embryo. They suggested that the protein complex was molecularly similar to the human vitronectin receptor. vitronectin as well as fibronectin (FFRENCH-CONSTANT and HyNES, 1988). Furthermore, a study of peanut agglutinin staining showed that the myocardium of the truncus arteriosus and the ventricle was distinguishable in chick embryos (FAzEL et al., 1989). This parallel might indicate that the secretory function of the myocardium (KRUG et al., 1985) of the truncus arteriosus and the AV cushion area differ from each other in chick embryos.

The immunoreactivity to the anti-vitronectin antibody of the myocardium facing the AV cushions was increased transitorily during the period of the endocardial cell migration. It was reported that the level of fibronectin synthesis in the myocardium was temporarily elevated at early stage of development, and diminished at a later stage (FFRENCH-CONSTANT and HYNES, 1988). The amount of fibronectin within the AP septum also decreased after division of the truncus arteriosus (Sumida et al., 1989a). We did not ascer- 
$\begin{array}{llllllll}1 & 2 & 3 & 4 & 5 & 6 & 7 & 8\end{array}$

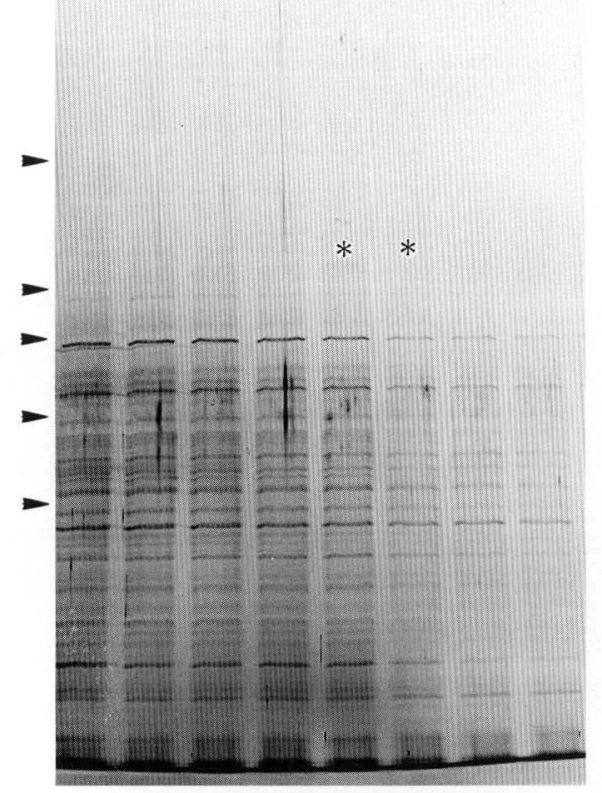

910111213141516

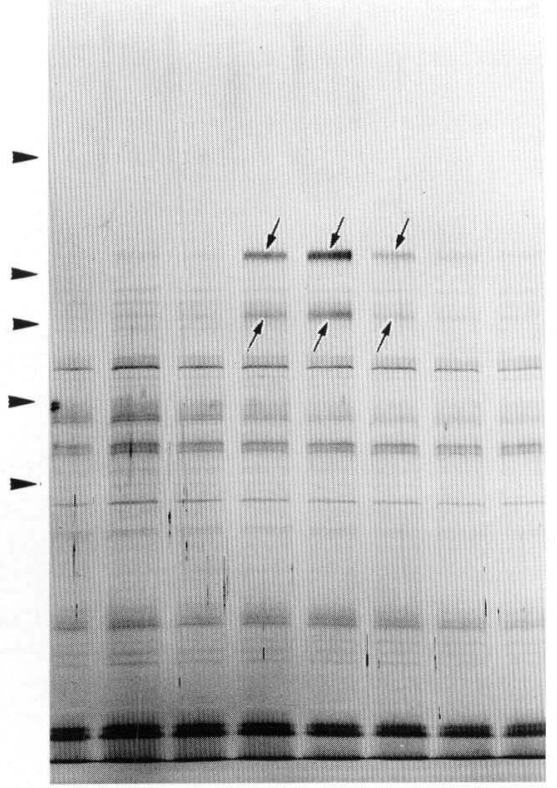

Fig. 6. SDS-PAGE of elution fraction from the GRGDSP column 'described by PYTELA et al. (1987). The gells were silver stained. Chick embryos incubated for 10 days and a fresh human placenta were washed in cold PBS to remove blood. The specimens were homogenized in PBS with $1 \mathrm{mM} \mathrm{CaCl}, 1 \mathrm{mM} \mathrm{MgCl}$ and $50 \mathrm{mM}$ octyl- $\beta$-D-thioglucopyranoside. Soluble proteins were applied to the GRGDSP-sepharose 4B column. RGD binding proteins were eluted by solution containing the GRGDSP synthesized peptide. Only a small amount of about 110-120 Kd protein (asterisks) from the chick embryos (lanes 1-8) was eluted by the solution, whereas the $125 / 115 \mathrm{Kd}$ vitronectin receptor complex (arrows) from the human placenta (lanes 9-16) was eluted from the same column. The approximately $110-120 \mathrm{Kd}$ protein might be glycoprotein IIIa or possibly $\beta$-subunit of chick integrin (see the footnote on p. 86). Arrowheads indicate molecular weights $(200,000,116,000,94,000,67,000,43,000)$.

tain at which stage immunoreactivity to the antibody of the swellings and cushions decreases or disappears. However, the transitory increase of the immunoreactivity to the anti-vitronectin antibody in the myocardium facing the AV cushions suggests that the myocardium supplies a high amount of vitronectin, especially for the endocardial cell migration.

In the present study, immunoreactivity to the antivitronectin antibody was not seen in the AP septum. This result is very interesting because the AP septum is rich in fibronectin (ICARDO, 1985; SUMIDA et al., 1989a). The distinctive distribution of fibronectin and vitronectin suggests that fibronectin and vitronectin are functionally different in vivo. The origin of the cells within the AP septum is different from that of cushion mesenchymal cells. Migrating cells withhin the AP septum derive from the neural crest (KIRBY et al., 1983; SumidA et al., 1989b), and are fibronectin receptor-rich (Sumida et al., 1989a). Thus, it is suggested that cells which have the fibronectin receptor migrate into the fibronectin-rich pathways, and cells which have the vitronectin receptor migrate into vitronectin-rich pathways. An immunocytochemical study showed that the vitronectin receptor aggregates on the cell surface depending on the ligand, but the fibronectin receptor aggregates independently of the ligand (SINGER et al., 1988). Yet another immunocytochemical study (DEJANA et al., 1988) showed that vitronectin and fibronectin induce the aggregation of their respective receptors in a specific manner. In any case, these observations suggest that the ligands control cell behavior. The distinctive distribution of the two glycoproteins may be important in cardiac morphogenesis. 
Acknowledgment. We thank Prof. M. YASUDA (Dept. Anat. Sch. Med. Hiroshima Univ.) for his critical reading of the manuscript.

\section{REFERENCES}

Barnes, D. W. and G. SATo: Serum-free cell culture: a unifying approach. Cell 22: 649-655 (1980).

BARNeS, D. W. and J. Silnutzer: Isolation of human serum spreading factor. J. Biol. Chem. 258: 12548-12552 (1983).

Dejana, E., S. Colella, G. Conforti, M. Abbadini, M. Gaboli and P. C. Marchisio: Fibronectin and vitronectin regulate the organization of their respective Arg-Gly-Asp adhesion receptors in cultured human endothelial cells. J. Cell Biol. 107: 1215-1223 (1988).

Duband, J.-L., S. Rocher, W. -T. Chen, K. M. Yamada and J. P. ThierY: Cell adhesion and migration in the early vertebrate embryo: Location and possible role of the putative fibronectin receptor complex. J. Cell Biol. 102: 160-178 (1986).

Fazel, A. R., R. P. Thompson, H. Sumida and B. A. Schulte: Lectin histochemistry of the embryonic heart: Expression of the terminal and penultimate galactose residues in developing rats and chicks. Amer. J. Anat. 184: 85-94 (1989).

Frrench-Constant, C. and R. O. Hynes: Patterns of fibronectin gene expression and splicing during cell migration in chicken embryos. Development 104: 369382 (1988).

Fitzharris, T. P. and R. R. Markwald: Cellular migration through the cardiac jelly matrix: A stereoanalysis by high-voltage electron microscopy. Devel. Biol. 92: 315-329 (1982).

Funderburg, F. M. and R. R. Markwald: Conditioning of native substrates by chondroitin sulfate proteoglycans during cardiac mesenchymal cell migration. J. Cell Biol. 103: 2475-2487 (1986).

Hamburger, V. and H. L. Hamilton: A series of normal stages in the development of the chick embryo. J. Morphol. 88: 49-92 (1951).

Hayman, E. G., M. D. Pierschbacher, Y. Ohgren and E. Ruoslahti: Serum spreading factor (vitronectin) is present at the cell surface and in tissues. Proc. Nat. Acad. Sci. USA 80: 4003-4007 (1983).

ICARDo, J. M.: Distribution of fibronectin during the morphogenesis of the truncus. Anat. Embryol. 171: 193200 (1985).

ICARdo, J. M. and F. J. Manasek: An indirect immunofluorescence study of the distribution of fibronectin during the formation of the cushion tissue mesenchyme in the embryonic heart. Devel. Biol. 101: 336-345 (1984).

Kirby, M. L., T. F. Gale and D. E. Stewart: Neural crest cells contribute to normal aorticopulmonary septation. Science 220: 1059-1061 (1983).
Krug, E. L., R. B. Runyan and R. R. Markwald: Protein extracts from early embryonic hearts initiate cardiac endothelial cytodifferentiation. Devel. Biol. 112: 414-426 (1985).

Markwald, R. R., T. P. Fitzharris and W. N. Adams Sмiтн: Structural analysis of endocardial cytodifferentiation. Devel. Biol. 42: 160-180 (1975).

MarkWaLd, R. R., T. P. Fitzharris and F. J. Manasek: Structural development of endocardial cushions. Amer. J. Anat. 148: 85-120 (1977).

Nakamura, A. and F. J. Manasek: Cardiac jelly fibrils: Their distribution and organization. Birth Defects: Orig. Artic. Ser. 14 (7): 229-250 (1978).

Окамото, N.: Cardiac morphogenesis and teratogenesis. Congenital Anom. 28(Suppl.): S103-S117 (1988).

Pytela, R., M. D. Pierschbacher, S. Argraves, S. Suzuki and E. Ruoslahti: Arginine-Glycine-Aspartic acid adhesion receptors. Methods Enzymol. 144: 475489 (1987).

Ruoslahti, E. and M. D. Pierschbacher: New perspectives in cell adhesion: RGD and integrins. Science 238: 491-497 (1987).

Singer, I. I., S. ScotT, D. W. KaWKa, D. M. KaZaZis, J. Gailit and E. Ruoslahti: Cell surface distribution of fibronectin and vitronectin receptors depends on substrate composition and extracellular matrix accumulation. J. Cell Biol. 106: 2171-2182 (1988).

Sumida, H., H. Nakamura and Y. Satow: The localization of fibronectin and $140 \mathrm{Kd}$ fibronectin receptor in the truncus arteriosus of the chick embryonic heart. Arch. Histol. Cytol. 52: 31-36 (1989a).

Sumida, H., N. Akimoto and H. Nakamura: Distribution of the neural crest cells in the heart of birds: a three dimensional analysis. Anat. Embryol. 180: 29-35 (1989b).

Sumida, H., H. Nakamura and Y. Satow: Distribution of vitronectin and its receptor in embryonic human heart. Ann. New York Acad. Sci. (in press).

Suzuki, S., A. Oldberg, E. G. Hayman, M. D. PierschBACHER and E. Ruoslahti: Complete amino acid sequence of human vitronectin deduced from cDNA. Similarity of cell attachment sites in vitronecitin and fibronectin. EMBO J. 4: 2519-2524 (1985).
Dr. Hiroshi Sumida
Department of Geneticopathology
Research Institute for Nuclear Medicine and Biology
Hiroshima University
1-2-3 Kasumi, Minami-ku
Hiroshima, 734 Japan
隅田寛
734 広島市南区霞 1 丁目 2 番 3 号
広島大学原爆放射能医学研究所
遺伝・優生学部門 